\title{
Heartbeat: therapeutic targets for prevention of calcific aortic valve stenosis
}

Current management of calcific aortic valve stenosis (CAVS) is limited to palliation of end-stage disease with valve replacement to relieve left ventricular outflow obstruction. Rather than treating the mechanical consequences of severe CAVS, identification of causal disease pathways at the tissue level might lead to medical therapies that could actually prevent or delay the pathological changes in the valve leaflets. Serum levels of lipoprotein-associated phospholipase A2 (Lp-PLA2) activity are associated with the presence of CAVS; however, it has been unclear whether this association is due to a cause-effect relationship. In this issue of Heart, Perrot and colleagues ${ }^{1}$ used genetic association studies from eight cohorts to show that CAVS was not associated with any of four single nucleotide polymorphisms that are associated with Lp-PLA2 activity or mass. These findings suggest that although Lp-PLA2 activity is a biomarker for CAVS unfortunately, it is unlikely to be a therapeutic target (figure 1).

In an editorial, Zheng and Dweck ${ }^{2}$ discuss this article, summarise current ongoing trials of medical therapy for CAVS (table 1) and comment: 'Strong evidence points towards elevated $\mathrm{Lp}(\mathrm{a})$ levels and its associated oxidised phospholipids (OxPL) as causal risk factors for CAVS, suggesting that targeting this lipid-driven, inflammatory pathway has a real chance to translate into therapy capable of mitigating disease. The current study suggests that this association is not mediated by Lp-PLA2 and underlines the importance of scrutinising whether biological factors within pathophysiological pathways are merely biomarkers or actually represent a feasible and causal target.'

Rheumatic heart disease (RHD) remains the primary cause of valve disease worldwide and contributes significantly to maternal and fetal morbidity and mortality. In a study by Baghel and colleagues ${ }^{3}$ of 681 pregnant women with RHD, adverse cardiovascular evens occurred in about $15 \%$ of pregnancies. Multivariable

Correspondence to Professor Catherine M Otto, Division of Cardiology, University of Washington, Seattle,WA 98195, USA; cmotto@uw.edu predictors of adverse outcomes during pregnancy were prior adverse cardiovascular events, lack of appropriate medical

therapy, severity of mitral stenosis, valve replacement and pulmonary hypertension. Based on this analysis, the authors propose

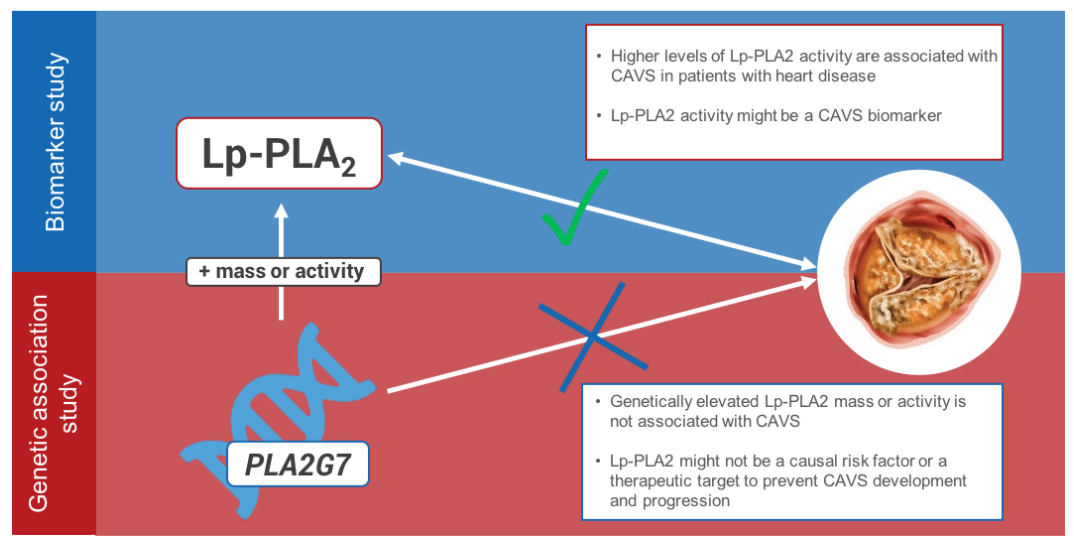

Figure 1 Higher Lp-PLA2 activity is significantly associated with the presence of CAVS in patients with heart disease, but variants influencing Lp-PLA2 mass or activity are not associated with CAVS in this large genetic association study. CAVS, calcific aortic valve stenosis; Lp-PLA2, lipoprotein-associated phospholipase A2.

Table 1 Ongoing randomised clinical trials of medical therapies in aortic stenosis

\begin{tabular}{|c|c|c|}
\hline Study & Target & Treatment \\
\hline \multicolumn{3}{|l|}{ Lipid-driven inflammation pathways } \\
\hline $\begin{array}{l}\text { PCSK9 inhibitors in the progression of aortic stenosis } \\
\text { (NCT03051360) }\end{array}$ & $\begin{array}{l}\text { ApoB-containing } \\
\text { lipoproteins; PCSK9. }\end{array}$ & $\begin{array}{l}\text { Biweekly injection of PCSK9 inhibitor } \\
\text { versus placebo. }\end{array}$ \\
\hline $\begin{array}{l}\text { EAVaLL_Early Aortic Valve Lipoprotein (a) Lowering } \\
\text { (NCT02109614) }\end{array}$ & Lipoprotein(a). & $\begin{array}{l}\text { Daily extended-release niacin 1500- } \\
2000 \mathrm{mg} \text { versus placebo. }\end{array}$ \\
\hline \multicolumn{3}{|l|}{ Calcification pathways } \\
\hline $\begin{array}{l}\text { SALTIRE II-Study Investigating the Effect of Drugs Used } \\
\text { to Treat Osteoporosis on the Progression of Calcific Aortic } \\
\text { Stenosis } \\
\text { (NCT02132026) }\end{array}$ & Mineral metabolism. & $\begin{array}{l}\text { Alendronic acid }(n=50) \text { versus placebo } \\
\text { tablets }(n=25) . \\
\text { Denosumab }(n=50) \text { versus placebo } \\
\text { injections }(n=25) .\end{array}$ \\
\hline $\begin{array}{l}\text { BASIK2 - Bicuspid Aortic Valve Stenosis and the Effect of } \\
\text { vltamin K2 on Calciummetabolism on 18F-NaF PET/MRI } \\
\text { (NCT02917525) }\end{array}$ & $\begin{array}{l}\text { Vitamin K2-Matrix Gla } \\
\text { protein. }\end{array}$ & $\begin{array}{l}\text { Daily vitamin K2 } 360 \mu \mathrm{g}(\mathrm{n}=22) \text { versus } \\
\text { placebo }(\mathrm{n}=22) \text {. }\end{array}$ \\
\hline
\end{tabular}

Table 2 New prognostic score (DEVI's score) to predict composite adverse cardiac outcome in pregnant women with rheumatic valvular heart disease

\begin{tabular}{ll}
\hline Predictor & Score \\
\hline Prior cardiovascular event* & +4.0 \\
\hline Pulmonary hypertension & +4.0 \\
\hline Taking cardiac medications & -1.0 \\
\hline Severe mitral stenosis & +4.0 \\
Moderate mitral stenosis & +2.0 \\
\hline Mild mitral stenosis & +1.0 \\
Prosthetic heart valve & +2.0 \\
\hline $\begin{array}{l}\text { Score is calculated by adding the individual score for the presence of each parameter and its range (minimum-maximum) is 0-12. A score of } 5 \\
\text { or more is associated with high risk of adverse cardiac outcome. } \\
\text { *Prior cardiovascular events defined as the occurrence of one or more of the following: heart failure arrythmia, infective endocarditis and } \\
\text { thromboembolic events. }\end{array}$ & \\
DEVI's Score, aDverse cardiac Events in Valvular rheumatic heart disease In pregnancy. &
\end{tabular}






Figure 2 Left ventricular global longitudinal strain to differentiate between mutation-positive sarcomeric hypertrophic cardiomyopathy and cardiac amyloidosis. (A) Apical four-chamber view of a 66-year-old patient known with mutation-positive hypertrophic cardiomyopathy. The thickness of the septum was $28 \mathrm{~mm}$ and the left ventricular ejection fraction was $55 \%$. (B) The polar map shows markedly impaired longitudinal strain in the septal mid and basal areas and the global longitudinal strain is impaired (-13.6\%). (C) Apical four-chamber view of a 75-year-old patient diagnosed with light chain amyloidosis. There is concentric hypertrophy of the left ventricle and the ejection fraction is $56 \%$. Based on speckle tracking echocardiography analysis, the left ventricular global longitudinal strain is impaired (-12.2\%), with typical sparing of the longitudinal strain values in the apical segments (D). ANT, anterior; ANT SEPT, anteroseptal; GS, global strain; INF inferior; LAT, lateral; POST, posterior; SEPT, septal.

a risk score from pregnant women with RHD (table 2).

Commenting on this paper, Elkayam and Shmueli $^{4}$ point out that in about one-fourth of women, the diagnosis of RHD was not known prior to pregnancy and that a late diagnosis often was associated with adverse outcomes. Their editorial provides a concise summary of optimal management of pregnant women with RHD. They conclude 'With proper evaluation and risk stratification prior to pregnancy, a close multidisciplinary follow-up during pregnancy,

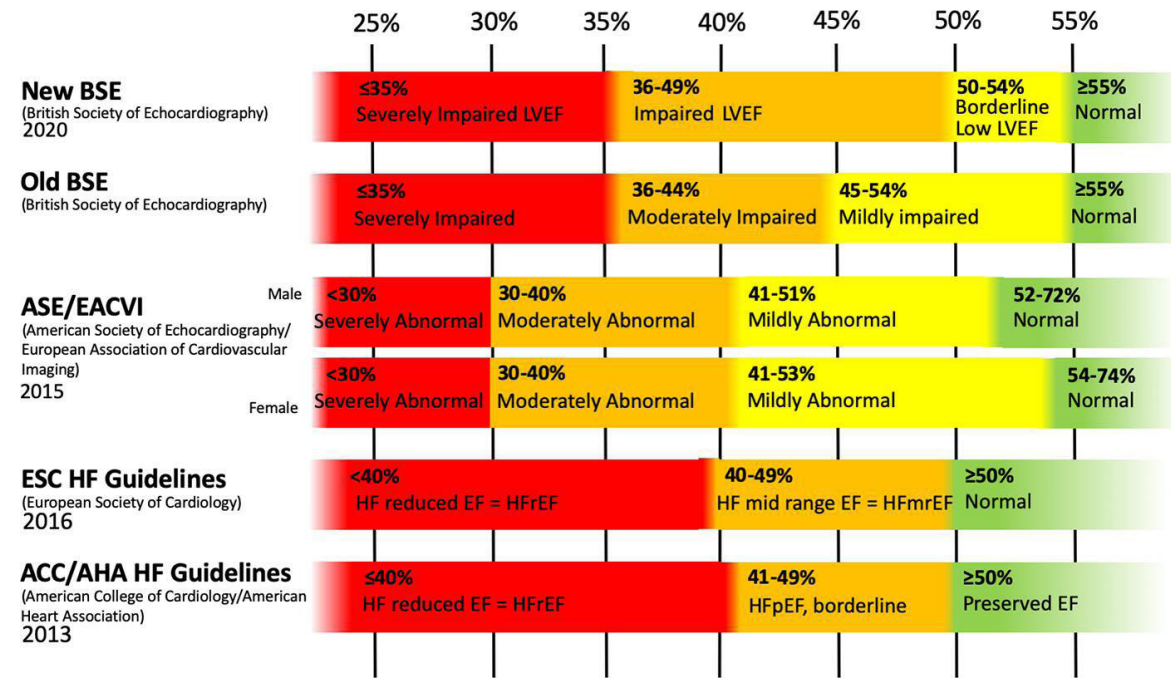

Figure 3 Categories of left ventricular ejection fraction. $\mathrm{EF}$, ejection fraction; $\mathrm{HF}$, heart failure; LVEF, left ventricular ejection fraction. and close monitoring during labour and delivery as well as the early postpartum period most complications can be prevented.'

The importance of psychosocial factors in cardiovascular disease (CVD) prevalence and outcomes is increasingly recognised. Using data from the English Longitudinal Study of Ageing, $\mathrm{Bu}$ and colleagues ${ }^{5}$ found that loneliness was associated with CVD, independent of possible confounders and other risk factors, with a $30 \%$ higher risk of a new CVD diagnosis in the most lonely people compared with the least lonely people. As O'Keefe and colleagues ${ }^{6}$ point out, this data is especially important now in the context of social distancing and stay-at-home recommendations and they offer several approaches to mitigating loneliness during the COVID-19 pandemic.

The Education in Heart article ${ }^{7}$ in this issue focuses on the clinical use and prognostic implications of echocardiographic speckle tracking measurements of global longitudinal strain to detect and quantify early systolic dysfunction of the left ventricle (figure 2).

Our Cardiology-in-Focus article by Hudson and Pettit ${ }^{8}$ provides a clear-eyed but brief discussion and outstanding graphic of the challenges in reconciling the varying definitions of the 'normal' values for left ventricular ejection fraction, as stated in different guidelines (figure 3).

Funding The authors have not declared a specific grant for this research from any funding agency in the public, commercial or not-for-profit sectors.

Competing interests None declared.

Patient and public involvement Patients and/ or the public were not involved in the design, or conduct, or reporting, or dissemination plans of this research.

Patient consent for publication Not required.

Provenance and peer review Commissioned; internally peer reviewed.

(c) Author(s) (or their employer(s)) 2020. No commercial re-use. See rights and permissions. Published by BMJ.

\section{Check for updates}

To cite Otto CM. Heart 2020;106:1369-1371.

Heart 2020;106:1369-1371

doi:10.1136/heartjnl-2020-318014

ORCID iD

Catherine M Otto http://orcid.org/0000-0002-05279392

\section{REFERENCES}

1 Perrot N, Thériault S, Rigade S, et al. Lipoproteinassociated phospholipase A2 activity, genetics 
and calcific aortic valve stenosis in humans. Heart 2020;106:1407-12.

2 Zheng KH, Dweck MR. Quest for pharmacotherapy in aortic valve stenosis: the lipid hypothesis. Heart 2020;106:1376-7.

3 Baghel J, Keepanasseril A, Pillai AA, et al. Prediction of adverse cardiac events in pregnant women with valvular rheumatic heart disease. Heart 2020;106:1400-6.
4 Elkayam U, Shmueli H. Pregnancy in women with rheumatic valve disease: how to improve the outcome? Heart 2020;106:1374-5.

5 Bu F, Zaninotto P, Fancourt D. Longitudinal associations between loneliness, social isolation and cardiovascular events. Heart 2020;106:1394-9.

6 O'Keefe JH, O'Keefe EL, Baklanov DV, et al. Healing the suffering of the Lonely heart. Heart 2020;106:1372-3.
7 Abou R, van der Bijl P, Bax JJ, et al. Global longitudinal strain: clinical use and prognostic implications in contemporary practice. Heart 2020;106:1438-44.

8 Hudson S, Pettit S. What is 'normal' left ventricular ejection fraction? Heart 2020;106:1445-6. 